\author{
А.А. Кожаева \\ «Вот так и приходилося \\ все переживать». - Рец. на кн.: \\ Щербаков А., Козлова А., \\ Островская И. На сердце пали все \\ печали. Судьбы крестьян в XX веке. \\ Воспоминания. М.: Изд-во Agey \\ Tomesh, 2019. 432 с., ил.
}

DOI: 10.31518/2618-9100-2020-5-21

УДК 930.85

Выходные данные для цитирования:

Кожаева А.А. «Вот так и приходилося все переживать». - Рец. на кн.: Щербаков А., Козлова А., Островская И. На сердце пали все печали. Судьбы крестьян в XX веке. Воспоминания. М.: Изд-во Agey Tomesh, 2019. 432 с., ил. // Исторический курьер. 2020. № 5 (13). С. 249-256. URL: http://istkurier.ru/data/2020/ISTKURIER-20205-21.pdf

\section{A.A. Kozhaeva*}

\section{"That's how I had to Experience} Everything»". - Book Review: Shcherbakov A., Kozlova A., Ostrovskaya I. Na serdtse pali vse pechali. Sudby krestyan v XX veke. Vospominaniya [All the Sorrows Fell on My Heart. The Fate of the Peasants in the $20^{\text {th }}$ Century. Memories]. Moscow: Agey Tomesh Publishing House, 2019. 432 p., ill.

DOI: $10.31518 / 2618-9100-2020-5-21$

\section{How to cite:}

Kozhaeva A.A. "That's how I had to Experience Everything»". - Book Review: Shcherbakov A., Kozlova A., Ostrovskaya I. Na serdtse pali vse pechali. Sudby krestyan v XX veke. Vospominaniya [All the Sorrows Fell on My Heart. The Fate of the Peasants in the $20^{\text {th }}$ Century. Memories]. Moscow: Agey Tomesh Publishing House, 2019. 432 p., ill. // Historical Courier, 2020, No. 5 (13), pp. 249-256. [Available online:] http://istkurier.ru/data/2020/ ISTKURIER-2020-5-21.pdf

Abstract. In 2019, the international historical and educational, charitable and human rights society "Memorial" published a collection of peasant memoirs, including three ego-documents, the authors of which E.K. Makarova, N.I. Skrylev and A.I. Ponomarev, who were born in the early 19th century, describe various, including tragic aspects of their life, which fell on the first half of the century. In the texts, most of all attention is focused on the period of the 1930-1940s, the reflection of the peasants on the events that took place around them is presented: collectivization, industrialization and the Great Patriotic War. The publication is accompanied by a short introductory part, comments from the relatives of the authors of the memoirs, comments from publishers explaining the terms of the spoken village language and illustrative material. The collection, aimed at a wide range of readers, contains a small number of shortcomings associated with the external design of sources, but the internal content of the memoirs themselves draws special attention. The publishers of memoirs are distinguished by a painstaking and careful attitude towards ego - sources, the desire to preserve not only the stylistic features of the texts, but also the information contained in them about the inner world of the authors, the motivation of their actions, the logic of thinking. For researchers, the publication is of undoubted value as a rare reflection of the natives of the rural world on the realities of time and life in a country where depeasantization was carried out in harsh, violent forms.bI

Keywords: peasantry; peasant memories; ego-documents; publication of the memoirs and epistolary heritage; Stalinism; USSR.

The article has been received by the editor on 25.07.2020.

Full text of the article in Russian and references in English are available below.

\footnotetext{
* Кожаева Альбина Алексеевна, студент, Новосибирский государственный университет, Новосибирск, Россия, e-mail: a.kozhaeva18@mail.ru

Kozhaeva Albina A., Student, Novosibirsk State University, Novosibirsk, Russia, e-mail: a.kozhaeva18@mail.ru
} 
Аннотация. В 2019 г. международным историко-просветительским, благотворительным и правозащитным обществом «Мемориал» издан сборник крестьянских воспоминаний, включающий три эго-источника, авторы которых Е.К. Макарова, Н.И. Скрылев и А.И. Пономарев, родившиеся в начале XX в., описывают различные, в т.ч. трагические стороны их жизни, которые пришлись на первую половину века. В текстах больше всего внимания акцентируется на периоде 1930-1940-х гг., представлена рефлексия крестьян на происходившие вокруг них события: коллективизацию, индустриализацию и Великую Отечественную войну. Издание сопровождается краткой вводной частью, комментариями родственников авторов воспоминаний, примечаниями публикаторов, разъясняющими термины разговорного деревенского языка, и иллюстративным материалом. Сборник, ориентированный на широкий круг читателей, содержит небольшое количество недостатков, связанных с внешним оформлением источников, однако внутреннее содержание самих текстов воспоминаний обращает на себя особое внимание. Издателей воспоминаний отличает кропотливое и бережное отношение к эго-источникам, стремление сохранить не только стилистические особенности текстов, но и содержавшуюся в них информацию о внутреннем мире авторов, мотивацию их поступков, логику размышлений. Для исследователей издание представляет несомненную ценность как редкая рефлексия выходцев деревенского мира на реалии времени и жизни в стране, где раскрестьянивание осуществлялось в жестких, насильственных формах.

Ключевые слова: крестьянство; крестьянские воспоминания; эго-источники; публикация мемуарно-эпистолярного наследства; сталинизм, СССР.

В XX в. наблюдается рост самосознания личности, и не только интеллигенции и других городских слоев, как принято считать, но и различных групп крестьянства. Люди начинают осознавать себя, понимать свою роль в общественной жизни, переосмыслять события, очевидцами которых они были. С конца 1980-х гг., в связи с формированием в нашей стране такого междисциплинарного направления, как крестьяноведение, возник интерес ученых к фиксации и изучению рефлексии крестьян, посвященной событиям XX в. Это породило возникновение целого корпуса источников, получивших условное название «крестьянские воспоминания». Виднейшими представителями крестьяноведения являются Т. Шанин, Дж. Скотт, В.П. Данилов ${ }^{1}$, среди региональных историков В.А. Зверев ${ }^{2}$, Н.Н. Родигина ${ }^{3}$ и др. Нельзя не упомянуть также о работе Ш. Фицпатрик ${ }^{4}$, изучившей социальное и политическое поведение крестьянства раннесоветской эпохи. Особенность данного направления в том, что внимание исследователей сосредоточено на изучении личности крестьянина в историческом и социальном аспекте через дискурс, который ими создается. Исследования «крестьяноведов» позволяют заполнить пробелы в изучении социума, составить портрет «великого незнакомца» ${ }^{5}$.

Крестьянство на протяжении первой половины XX в. оставалось самой значимой социальной группой в структуре российского (советского) общества. Крестьяне становились не

\footnotetext{
${ }^{1}$ Рефлексивное крестьяноведение: Десятилетие исследований сельской России / под ред. Т. Шанина, А. Никулина, В. Данилова. М., 2002.

2 Зверев В.А. Крестьянское население Сибири в эпоху капитализма (проблемы физического и социального возобновления). Новосибирск, 1988; Зверев В.А. Дети - отцам замена: воспроизводство сельского населения Сибири (1861-1917 гг.). Новосибирск, 1993.

${ }^{3}$ Родигина Н.Н. Крестьянские эго-тексты как источник для реконструкции биографийпереселенцев второй половины XIX - начала XX в. // «История в человеке, попавшемся на ее дороге»: историческая биография в Сибири XIX-XXI веков (историографический, источниковедческий и методический аспекты): коллективная монография, посвященная памяти В.Ф. Цыбы. Новосибирск, 2018. С. 82-97.

${ }^{4}$ Фицпатрик Ш. Сталинские крестьяне: социальная история Советской России в 30-е годы: деревня. М., 2001.

${ }^{5}$ Великий незнакомец: крестьяне и фермеры в современном мире: пер. с англ. / сост. Т. Шанина; под ред. А.В. Гордона. М., 1992.
} 
только очевидцами, но и активными участниками государственных преобразований, однако по разным причинам (низкая грамотность значительной части деревни, традиционализм и обособленность от городского мира и др.) их голос (документально выраженная рефлексия) был слишком «тихим». Тем не менее пусть и относительно небольшое количество крестьянских воспоминаний доходят до нас через потомков выходцев из крестьянской среды. В связи с этим особую важность представляет публикация сборника «На сердце пали все печали. Судьбы крестьян в XX веке. Воспоминания» ${ }^{6}$ изданного международным историко-просветительским, благотворительным и правозащитным обществом «Мемориал».

Сборник крестьянских воспоминаний представляет прямой интерес для исследователей крестьянской повседневности. Его публикаторы сознательно не комментируют события, описываемые в тексте, ограничиваясь лишь небольшим вступлением перед документами, где сообщается о принципах выбора текстов для публикации, а также примечаниями относительно понятий из крестьянского языка и просторечия, употреблявшегося авторами. В сборник вошли три текста, переданные родственниками авторов в архив «Мемориала»: автобиография Евдокии Константиновны Макаровой, родословная Николай Иосифовича Скрылева и воспоминания Анфима Игнатьевича Пономарева. Е.К. Макарову и А.И. Пономарева скорее можно отнести к категории выходцев из крестьянской среды, поскольку в своей взрослой жизни они оказались уже в городских мирах. Н.И. Скрылеву удалось вернуться в крестьянский мир после войны, но мужчина стал совсем другим - его в полной мере можно считать «человеком войны».

Крестьянские воспоминания - источники, отражающие личностное восприятие событий, происходивших в окружающем мире, поэтому их справедливо относить к такому виду источников, как эго-документы (или эго-источники). Воспоминания являются произведениями, написанными от лица автора, рассказывающего о событиях, современником которых он был. Пишутся воспоминания обычно по памяти, нередко их пишет даже не сам человек, а тот, кому он это рассказывает (тогда воспоминания становятся устной историей), что не является редкостью среди малограмотного крестьянства. Корректировка часто ведет к тому, что первоначальная информация, приводимая автором дискурса, существенно меняется, а это необходимо учитывать при публикации и работе с данным видом источников.

При публикации крестьянских воспоминаний возникает ряд проблем, связанных прежде всего с объяснением происхождения источника, а также с его интерпретацией и передачей авторского языка. Конечно, желательно, чтобы при публикации эго-источников использовался первоисточник, который наиболее полно отражает непосредственно мысли автора, но он не всегда доступен публикаторам.

Крестьянские воспоминания хранятся прежде всего в семейных архивах. Первоисточниками всех документов, представленных в сборнике, были рукописные тексты, однако на данный момент сохранилась рукопись только А.И. Пономарева. Остальные же рукописи дошли до нас в переработке. В связи с этим возникает существенная проблема интерпретации источников, т.к. в процессе переработки оригиналы текстов Н.И. Скрылева и Е.К. Макаровой претерпели существенные изменения, о которых не сказано в самом сборнике, что естественно, т.к. первоисточники этих воспоминаний были утрачены, поэтому у составителей не было возможности провести критику источника.

Другая проблема - передача авторского языка. Выходцы из крестьянской среды в большинстве случаев оставались неграмотными или малограмотными, поэтому тексты тех из них, кто решил написать свою биографию, сложны для восприятия современным человеком. Например, рукопись А.И. Пономарева имела трудночитаемый вид: неразборчивые знаки препинания, произвольное написание слов, различное расстояние между буквами. Составителям сборника удалось сделать этот текст понимаемым для большинства читателей.

В целом можно сказать, что публикация сборника крестьянских воспоминаний рассчитана прежде всего на массового читателя. Визуальные источники, представленные фотографиями из личных архивов авторов воспоминаний, делают издание еще более

\footnotetext{
${ }^{6}$ На сердце пали все печали. Судьбы крестьян в XX веке. Воспоминания. М., 2019.
} 
интересным. Кроме того, составители несколько отступают от установленных правил издания исторических источников. Например, в начальных заметках перед каждым текстом сказано, что в них вносились пунктуационные и орфографические исправления, но в самих текстах это никак не обозначено. Представленных комментариев к текстам кажется явно недостаточно, авторы комментируют лишь отдельные непонятные современному читателю слова и выражения, однако часть устаревших слов и населенных пунктов просто упускается из вида составителей, не говоря уже о важных государственных событиях, которые также требуют комментирования.

Данные частные замечания, связанные с внешним оформлением источников, никак не умаляют достоинств сборника, поскольку внутреннее содержание самих воспоминаний обращает на себя особое внимание. Тексты, представленные в сборнике, описывают совершенно разные судьбы, что позволяет взглянуть на все стороны крестьянской жизни. Е.К. Макарова описала в своей автобиографии большой отрезок своей жизни с 1913 по 1977 г., где важнейшими составляющими ее биографии является коллективизация, жизнь в колхозе и жизнь в условиях немецкой оккупации. Н.И. Скрылев же рассказывает подробную биографию своих предков, о «раскулачивании» своей семьи, работе шахтером, но главным событием в его жизни становится Великая Отечественная война (эта часть его воспоминаний является самой содержательной). Воспоминания А.И. Пономарева описывают жизнь крестьянина, в молодости попавшего в лагерь по 58-й статье УК РСФСР и выжившего благодаря приобретенной специальности электросварщика.

Несмотря на разные судьбы авторов, есть то, что объединяет этих людей между собой: все являются выходцами из крестьянской среды, превращенной государством в расходный универсальный ресурс для собственной проводимой политики. Евдокия Константиновна Макарова, с детства помнившая о продовольственной политике советской власти в годы «военного коммунизма», когда деревня оказалась во власти комитетов бедноты, описала свое непонимание того, почему власть оказалась в руках людей, которые не вели и не собирались вести свое хозяйство, но отнимали его у других, которые все силы тратили на него. В годы НЭПа жизнь Е.К. Макаровой немного улучшилась (замужество, рождение детей, ведение хозяйства в отсутствие мужа - отходника), но затем началась коллективизация, с ее вынужденным вступлением в колхоз из-за непосильных для единоличников налогов. В колхозе женщина стала одним из лидеров благодаря своим качествам, однако с началом войны она вновь все потеряла. Особенно трагичным периодом в ее судьбе стала жизнь в оккупации и потеря близких ей людей (мужа, сына), а далее - переезд в город и работа простой техничкой. Перед нами - драматическая эго-история крестьянки, оказавшейся фактически, как и миллионы других, главой семьи не по своей воле, обеспечивавшей выживание своих уцелевших детей.

Судьба Н.И. Скрылева также сложна, хотя он единственный из авторов, кто остался жить и работать в селе в 1960-е гг. В период коллективизации отцу Н.И. Скрылева ложно приписали покупку земли и использование наемной силы, за что забрали все имущество, вынуждая детей побираться и работать в поле. По счастливой случайности отцу автора удалось снять с себя обвинение и вернуть дом, но мать из-за психологической травмы от происходящего умерла. Николай Иосифович вынужден был отправиться на заработки в шахты (для этого ему пришлось соврать о своем возрасте, т.к. ему было на тот момент всего 13 лет). А потом началась война и он, уйдя на фронт пятнадцатилетним, вернулся девятнадцатилетним героем, орденоносцем. В конце войны получил тяжелое ранение, от последствий которого так и не мог избавиться в оставшиеся годы жизни.

Политика раскрестьянивания привела к изменению образа и характера жизни огромного количества населения страны. Традиционные уклады крестьянской жизни, сталкиваясь с модернизационной политикой советской власти, частично исчезали, частично трансформировались. Крестьяне в свою очередь либо подстраивались под новые модерные реалии, либо же не желали мириться с ними, желая сохранить свои традиционные установки, но сделать это в условиях укрепления советской государственности было почти невозможно, поскольку 
каждый человек, не вписывавшийся в установленную государством систему, ставился для нее врагом, которого нужно либо уничтожить, либо перевоспитать.

Ярким примером данного процесса является жизнь и судьба Анфима Игнатьевича Пономарева. Он меньше других описывает конкретно крестьянскую жизнь, поскольку с 1930 г. он уже становится строительным рабочим, электросварщиком. В 1937 г. его арестовали по 58-й статье УК РСФСР и отправили в лагерь Апкашево (Западная Сибирь). Обращает на себя внимание тот факт, что автор нигде не указывает причины и обстоятельства его ареста, лишь в конце своего текста отмечает: «Все эта 58 статья, приписанная не виноватому ни в чем человеку». Интересно, что несмотря на все свои лишения в период сталинизма (арест, жизнь в лагере, сложности с поиском работы после освобождения из-за 58-й статьи), автор отзывается о самом «вожде» положительно. Казалось бы, автор сам критикует политику власти: объяснения этому дают его родственники, которые пишут, что Анфим Игнатьевич считал инициатором проведения репрессивно-карательной политики Л.П. Берию, но никак не И.В. Сталина.

Данные воспоминания примечательны еще и тем, что информация, представленная в них, является предметным полем семейной и гендерной истории. Женские воспоминания Е.К. Макаровой существенно отличаются от мужских воспоминаний Н.И. Скрылева и А.И. Пономарева. Евдокия Константиновна рассказывает о своей семье более эмоционально и полно, особенно ярко это проявляется в воспоминаниях о заботе о больном муже, о смерти ее родных в годы немецкой оккупации, а также в моментах, связанных с рождением ее детей. Мужчины же в своих воспоминаниях редко говорят о семье, исключением, пожалуй, является только воспоминания Н.И. Скрылева о его отце, который сыграл в его жизни очень важную роль, поскольку фактически один воспитал его. О жене Н.И. Скрылев говорит мало, хотя говорить было о чем. Она, как и он, испытала на себе ужасы войны, о чем мы узнаем не от ее мужа, а от их потомков. Его дети же фигурируют в тексте только в качестве адресатов его воспоминаний, но о их появлении и роли в его жизни совсем не сказано. А.И. Пономарев также не приводит каких-либо сведений о своей семье, кроме того, что семья столкнулась со сложностями после его заключения в лагерь.

Небольшое количество информации о семье в воспоминаниях мужчин может объясняться авторским стремлением показать наиболее важные, по их мнению, события своей жизни (война или работа строителем). Этот факт в свою очередь говорит о традиционных крестьянских ценностях о семье. Евдокия Константиновна - женщина, которая так или иначе является хранительницей домашнего очага, поэтому она просто не смогла проигнорировать факты о своей семейной жизни. Но несмотря на это, она является и исключением по отношению к традиционному облику сельской крестьянки, занимающейся домом, хозяйством и семьей. Макарова самостоятельно брала на себя ответственность, занимала должность бригадира в колхозе. Однако крестьян 1930-х гг. характеризует простой принцип «не высовывайся, а то будет хуже», поэтому очень редко кто-то из них стремился к должностям. Евдокия описывает случай, когда ее звали быть кладовщицей, но она не хотела, как в принципе и все: «Нет, нет, я неграмотная, насижу себе тюрьму» ${ }^{7}$. Кладовщицей в итоге она стала, а когда ее предлагали назначить председателем колхоза, то из-за страха она отказалась. Этот страх был вполне обоснован, т.к. председатель колхоза был ответственен за выполнение/невыполнение государственного плана, ситуация вдвойне усугублялась для женщины, которая согласно традиционному крестьянскому образу жизни не должна была «идти во власть». Поэтому Е.К. Макарова стала сторонником стратегии «пассивного приспособления» ${ }^{8}$, при которой она была готова сотрудничать с властью, но только в безопасных пределах.

Крестьянские воспоминания позволяют анализировать события, происходящие не только на макроуровне (исследование государства и общества), но и на микроуровне (жизнь конкретного человека и/или семьи), что позволяет реконструировать семейную историю.

\footnotetext{
${ }^{7}$ На сердце пали все печали... С. 90.

${ }^{8}$ Фицпатрик Ш. Сталинские крестьяне... С. 18-22.
} 
Воспоминания Е.К. Макаровой не дошли бы до публикаторов, если бы ее дальняя родственница (внучатая племянница) не задалась бы целью узнать историю своей семьи. Женщина, которая искала информацию о своем отце, фактически случайно узнала о том, что существует такой ценный для нее источник, каким была Макарова.

В крестьянских воспоминаниях, кроме собственно биографий, содержится также интересная информация о крестьянской повседневности, начиная с приема пищи (Евдокия Макарова описывает то, что пищу принимали всей семьей из общей тарелки по кругу), заканчивая яркими эпизодами традиционной крестьянской жизни (проверка способностей молодой жены к ведению хозяйства, в т.ч. встать первой в ряде женщин на сенокосе). Так, Николай Скрылев описывает, как происходили в его селе крестьянские кулачные бои, приводя подробные сведения о «правилах» боя («лежачих не бьют» ${ }^{9}$, «здорованье» ${ }^{10}$ и пр.). Авторы не случайно приводят информацию об этих и других крестьянских традициях, ведь последние являлись существенной частью их жизни. Здесь поднимается проблема связи поколений, поскольку именно от своих предков они получили эти знания, а теперь через свои тексты они хотят передать их своим детям и внукам. Авторы обращаются к своим детям, имитируя устную речь на бумаге. Николай Скрылев, описывая трудности военной жизни, своим детям пишет: «Вот видите, дети, у меня еше сохранились мозоли и их следы на правой руке, это память о войне» ${ }^{11}$. Евдокия Макарова завершает свои воспоминания фразой, которая означает, что именно ее дети должны продолжить семейную биографию: «Дальше пишите сами» ${ }^{12}$.

Особый интерес представляет фольклор, который до нас, современных людей, доходит через письменные и устные воспоминания. По этим фольклорным отрывкам мы можем судить об отношении крестьянства к власти. Е.К. Макарова вспоминает строчку из песни, которая была придумана про бедняков того времени: «Раньше Митька Седунов шарил по карманам, а теперь стал в сельсовете главным комиссаром» ${ }^{13}$. Фольклор, представленный в крестьянских воспоминаниях, является рефлексией свидетелей эпохи на происходящие вокруг них события: «говорят, что Ленин умер, я вчера его видал, без порток в одной рубашке пятилетку догонял» ${ }^{14}$, «все колхозы, все колхозы, записались все в колхоз, а осталось от колхоза не пришей собаке хвост» ${ }^{15}$. Данная цитата интересна еще и с точки зрения крестьян на происходившие в стране и за ее пределами события. Фольклорные вставки, содержащиеся в крестьянских воспоминаниях, являются уникальными, ведь они существовали только в то время и только в устной форме, поэтому мы можем получить такой вид информации только из эго-источников, т.к. в делопроизводственных и статистических данных это не отображалось, а периодика того времени не позволила бы такое даже печатать.

Авторы ставят свое жизнеописание в контекст эпохи, но особенно не отзываясь о «большой политике». Гораздо чаще в их текстах присутствует информация о сельскохозяйственной работе, об особенностях работы в шахте, о работе плотника, чем их мнения о революции, о внешней политике страны, о коллективизации и пр. Информация об этих фактах хоть и частично присутствует в их текстах, но выступает вторым планом, что, с одной стороны, позволяет понять психологию крестьян, для которых события играли хоть какуюто роль, только если непосредственно были связаны с их жизнью. Примером может стать рефлексия А.И. Пономарева на тему финской миграции в Автономную Карельскую ССР в 1930-х гг. Подготовка Финляндии к войне вряд ли затронула бы мысли мужчины, если бы он не столкнулся с финнами, когда работал в Карелии. Возвращаясь к вопросу о комментировании авторами происходивших событий, стоит сказать, что только миграция финнов из

\footnotetext{
${ }^{9}$ На сердце пали все печали... С. 187.

${ }^{10}$ Там же. С. 187.

${ }^{11}$ Там же. С. 269

12 Там же. С. 169.

${ }^{13}$ Там же. С. 34.

14 Там же. С. 38.

15 Там же. С. 91.
} 
США и Канады в Автономную Карельскую область ССР была подробно прокомментирована историком А.И. Бутвилло ${ }^{16}$, никакие другие исторические факты в сборнике не комментируются.

Сборник завершается статьей-рецензией С.А. Красильникова «Три судьбы - лихолетье одно» ${ }^{17}$, где автор рассуждает о проблемах, которые поднимаются в текстах источников, и делает справедливый вывод о том, что крестьянство, используемое в качестве «расходного материала» в 1930-е гг., стало основой победы страны в Великой Отечественной войне. Действительно, крестьянские воспоминания, представленные в сборнике и акцентирующие внимание на 1930-1940-х гг. ХХ в., показывают не просто крестьянскую жизнь, а повседневные практики выживания народа в тех условиях, которые были установлены тоталитарным государством.

Задача социальной и политической адаптации человека в новом постреволюционном обществе была трудной. Кто-то с этой задачей успешно справлялся, а кто-то, напротив, становился для этого общества «лишним» (это подтверждается сведениями о количестве маргинального населения страны: «лишенцы», ссыльные, спецпоселенцы и пр.). Судьбы Е.К. Макаровой, А.И. Пономарева и Н.И. Скрылева - это конкретные случаи адаптации и интегрирования крестьянства в структуру постреволюционного общества. Обращение к крестьянским воспоминаниям дает возможность реконструировать язык крестьянства, а также мотивы, психологию и практики социального поведения выходцев из данной социальной группы. В связи с этим публикация данных источников очень важна, поэтому хотелось бы, чтобы общество «Мемориал» не останавливалось на выпуске данного сборника, а продолжало издание других крестьянских воспоминаний.

\section{Лumepamypa}

Великий незнакомец: крестьяне и фермеры в современном мире: пер. с англ. / сост. Т. Шанина; под ред. А.В. Гордона. М.: Издательская группа «Прогресс» - «ПрогрессАкадемия», 1992. 432 с.

Зверев В.А. Дети - отцам замена: воспроизводство сельского населения Сибири (18611917 гг.). Новосибирск: Изд-во НГПИ, 1993. 244 с.

Зверев B.A. Крестьянское население Сибири в эпоху капитализма (проблемы физического и социального возобновления). Новосибирск: Изд-во НГПИ, 1988. 88 с.

На сердце пали все печали. Судьбы крестьян в XX веке. Воспоминания / ред.-сост. А. Щербаков, А. Козлова, И. Островская. М.: Изд-во Agey Tomesh, 2019. 432 с., ил.

Рефлексивное крестьяноведение: десятилетие исследований сельской России / под ред. Т. Шанина, А. Никулина, В. Данилова. М.: МВСШЭН, РОССПЭН, 2002. 588 р.

Родигина Н.Н. Крестьянские эго-тексты как источник для реконструкции биографий переселенцев второй половины XIX - начала XX в. // «История в человеке, попавшемся на ее дороге»: историческая биография в Сибири XIX-XXI веков (историографический, источниковедческий и методический аспекты): коллективная монография, посвященная памяти В.Ф. Цыбы. Новосибирск: Изд-во НГПУ, 2018. С. 82-97.

Фицпатрик Ш. Сталинские крестьяне: социальная история Советской России в 30-е годы: деревня. М.: Российская политическая энциклопедия, 2001. 422 с.

\section{References}

Danilov, V., Nikulin, A., Shanin, T. (Eds.). (2002). Refleksivnoye krestyanovedeniye: Desyatiletiye issledovaniy selskoy Rossii [Reflexive Peasant Studies: A Decade of Studies on Rural Russia]. Moscow: MVSShEN, ROSSPEN, 2002. 588 p.

\footnotetext{
${ }^{16}$ На сердце пали все печали... С. 378.

${ }^{17}$ Красильников С.А. Три судьбы - лихолетье одно // На сердце пали все печали... С. 423-430.
} 
Fitzpatrik, Sh. (2001). Stalinskie krestiane: Sotsialnaia istoriia sovetskoi Rossii v 30-e gody: derevnia [Stalin peasants. Social history of Soviet Russia in the 30-ies: village]. Moscow: ROSSPEN. 421 p.

Rodigina, N.N. (2018) Krestyanskiye ego-teksty kak istochnik dlya rekonstruktsii biografiy pereselentsev vtoroy poloviny $X I X-$ nachala $X X v$. [Peasant ego-texts as a source for reconstructing the biographies of migrants of the second half of the $19^{\text {th }}$ - beginning of the $20^{\text {th }}$ century]. In "Istoriya $v$ cheloveke, popavshemsya na ee doroge": istoricheskaya biografiya v Sibiri XIX-XXI vekov (istoriograficheskiy, istochnikovedcheskiy i metodicheskiy aspekty): kollektivnaya monografiya, posvyashchennaya pamyati V.F. Cyby. Novosibirsk, Novosibirsk State Pedagogical University, pp. 82-97.

Shanina, T. (1992). Velikii neznakomets. Krestiane i fermery $v$ sovremennom mire [The great unknown. Peasants and farmers in the modern world]. Moscow: Progress. $432 \mathrm{p}$.

Shcherbakov, A., Kozlova, A., Ostrovskaya, I. (Eds.). (2019). Na serdtse pali vse pechali. Sudby krestyan $v X X$ veke. Vospominaniya [All the sorrows fell on my heart. The fate of the peasants in the $20^{\text {th }}$ century. Memories]. Moscow: Agey Tomesh Publishing House. 432 p., ill.

Zverev, V.A. (1988). Krestyanskoye naseleniye Sibiri v epokhu kapitalizma (problemy fizicheskogo i sotsialnogo vozobnovleniya) [Peasant population of Siberia in the era of capitalism (problems of physical and social renewal)]. Novosibirsk: Novosibirsk State Pedagogical Institute. 88 p.

Zverev, V.A. (1993). Deti - ottsam zamena: Vosproizvodstvo selskogo naseleniya Sibiri (18611917 gg.) [Children - fathers replacement: The reproduction of the rural population of Siberia (1861-1917)]. Novosibirsk: Novosibirsk State Pedagogical Institute. 244 p.

Статья поступила в редакцию 25.07.2020 г. 